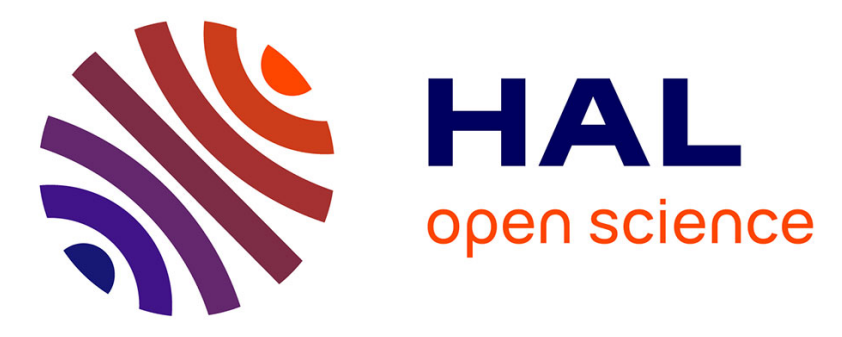

\title{
Status of the light ion source developments at CEA/Saclay
}

\author{
R. Gobin, P.-Y. Beauvais, D. Bogard, G. Charruau, O. Delferrière, D. de \\ Menezes, A. France, R. Ferdinand, Y. Gauthier, F. Harrault, et al.
}

\section{- To cite this version:}

R. Gobin, P.-Y. Beauvais, D. Bogard, G. Charruau, O. Delferrière, et al.. Status of the light ion source developments at CEA/Saclay. 10th International Conference on Ion Sources, Sep 2003, Dubna, Russia. pp.1414-1416, 10.1063/1.1690474 . in2p3-00023404

\section{HAL Id: in2p3-00023404 https://hal.in2p3.fr/in2p3-00023404}

Submitted on 8 Jan 2007

HAL is a multi-disciplinary open access archive for the deposit and dissemination of scientific research documents, whether they are published or not. The documents may come from teaching and research institutions in France or abroad, or from public or private research centers.
L'archive ouverte pluridisciplinaire HAL, est destinée au dépôt et à la diffusion de documents scientifiques de niveau recherche, publiés ou non, émanant des établissements d'enseignement et de recherche français ou étrangers, des laboratoires publics ou privés. 


\title{
STATUS OF THE LIGHT ION SOURCE DEVELOPMENTS AT CEA/SACLAY
}

R. Gobin*, P-Y. Beauvais, D. Bogard, G. Charruau, O. Delferrière, D. De Menezes, A. France, R. Ferdinand, Y. Gauthier,

F. Harrault, P. Mattéi,

Commissariat à l'Energie Atomique, CEA-Saclay, DSM/DAPNIA, 91191 Gif sur Yvette Cedex, France

K. Benmeziane,

CEA/Saclay and LPGP (Associé au CNRS), Université de Paris-Sud, 91405 Orsay Cedex, France

P. Leherissier, J-Y. Paquet,

GANIL, Bd Henri Becquerel, 14076 Caen Cedex 5. France

P. Ausset, S. Bousson, D. Gardes, A. Olivier,

Centre National de la Recherche Scientifique, IN2P3, IPN, 91405 Orsay Cedex, France

L. Celona,

Istituto Nationale de Fisica Nucleare, LNS, via Sofia, Catania, Italy

J. Sherman,

Los Alamos National Laboratory, Los Alamos, N.M. 87 545, USA

* E-mail : rjgobin@cea.fr

\begin{abstract}
SILHI (High Intensity Light Ion Source) is an ECR ion source producing high intensity proton or deuteron beams at $95 \mathrm{keV}$. It is now installed in the IPHI site building, on the CEA/Saclay center. IPHI is a front end demonstrator of high power accelerator. The source regularly delivers more than $130 \mathrm{~mA}$ protons in CW mode and already produced more than $170 \mathrm{~mA}$ deuterons in pulsed mode at nominal energy. The last beam characterisations, including emittance measurements, space charge compensation analysis and diagnostic improvements, will be reported. Taking into account the SILHI experience, new developments are in progress to build and test a $5 \mathrm{~mA}$ deuteron source working in $\mathrm{CW}$ mode. This new source will also operate at $2.45 \mathrm{GHz}$ and permanent magnets will provide the magnetic configuration. This source, of which the design will be discussed, will have to fit in with the SPIRAL 2 accelerator developed at GANIL to produce Radioactive Ion Beams. The $\mathrm{H}^{-}$test stand status is briefly presented here and detailed in companion papers.
\end{abstract}

This work is partly supported by the European Commission under contract $n^{\circ}$ : HPRI-CT-2001-50021.

\section{INTRODUCTION}

For several years, CEA and CNRS have undertaken an important R\&D program on very high beam power accelerators. In a first step a High Intensity Light Ion Source (SILHI) has been developed to be the injector of such a machine. The SILHI main objective is to produce $100 \mathrm{~mA}$ proton $\mathrm{CW}$ beam currents at $95 \mathrm{keV}$ with rms normalized emittances lower than $0.2 \pi \mathrm{mm}$.mrad. These developments are carried out in the framework of the accelerator front end prototype IPHI (High Intensity Proton Injector) [1]. Other high intensity experiments with SILHI are also devoted to the production of deuterons for irradiation tools. Deuterons are now also demanded by the future SPIRAL 2 facility, to enlarge the radioactive ion beam production. A specific paper [2] from GANIL group largely develops the SPIRAL 2 requests. At Saclay, a "low" intensity (5 mA) deuteron source is presently under study. The negative ion test stand which delivered its first $\mathrm{H}^{-}$ions at the beginning of 2002 is still under development.

The SILHI ECR ion source, operating at $2.45 \mathrm{GHz}$, is regularly producing more than $100 \mathrm{~mA}$ proton beams [3]. Section II presents the recent measurements performed since the restart of the source in its new location. It also reports on emittance measurements performed before the displacement. The deuteron source studies undertaken to fit in with the SPIRAL 2 demand are reported in section III where the permanent magnet structure and the extraction system are presented.

The recent $\mathrm{H}^{-}$ion source development is briefly summarized. Two companion papers will develop either the theoretical approach [4] or the experimental results [5] obtained since the plasma chamber is divided in 2 parts by a stainless steel grid.

\section{PROTON BEAM MEASUREMENTS}

\section{II-1 Easy restart}

The installation was completely disassembled to be moved in the IPHI building. In 2001, an oil contamination led to important troubles with low proton fraction and high spark rate [3]. The 2 turbomolecular pumping groups were serviced and all the vacuum chambers were chemically cleaned. To avoid new contamination, dry pumps were envisaged. But this kind of pump is not able to evacuate the hydrogen gas flow. So the first part of the LEBT (Low Energy Beam Transport) line is equipped with a classical pump and the second part with a dry pump.

By tuning the source parameters at standard values, the first extracted beam reached more than $70 \mathrm{~mA}$ within a few minutes. And it took only a few days to extract more than $100 \mathrm{~mA}$. A few weeks later, while the source was producing a $93 \mathrm{~mA}$ total beam at $95 \mathrm{kV}$ during a 70 hour period, only one beam trip occurred for 2.5 minutes. The same behaviour was already observed after the first moving in 1998. 


\section{II-2 Emittance measurements}

The Emittance Measurement Unit (EMU) allows separate beam species analysis and emittance measurements for the desired particle beam. It is made of 3 parts:

- the $0.2 \mathrm{~mm}$ diameter tantalum sampler located in a water cooled copper block,

- the permanent magnet Wien filter with adjustable electric field [6]

- and finally the wire for beamlet intensity measurement. A polarized plate located in front of the wire minimizes the secondary electron effects.

By using a stepping motor, the sampler is moved along a beam diameter with steps as low as $0.1 \mathrm{~mm}$. For each position, it is possible to perform species analysis by varying the electric field from 0 to $10 \mathrm{kV} / \mathrm{cm}$. To do emittance measurements, the beamlet divergence is deduced from the width of the collected current peak on the wire. The sampler position and the average potential value for the peak give the global divergence of the considered beam. Automatic procedures allow emittance measurements within a few minutes.

The EMU was first installed at the exit of the accelerator column. The proton beam parameters were $97 \mathrm{~mA}$ intensity $(120 \mathrm{~mA}$ total) and $95 \mathrm{keV}$ energy. By varying the intermediate electrode voltage (named HTEI) from 27 to $49 \mathrm{kV}$, the emittance value ranges from 0.155 to $0.175 \pi \mathrm{mm} . \mathrm{mrad}$. The minimum value occurs at HTEI $=43 \mathrm{kV}$.

Then the EMU was moved to the end of the LEBT. As a result, the measurements indicate an emittance growth and a small variation of the emittance value (from 0.269 to $0.285 \pi \mathrm{mm} . \mathrm{mrad}$ ) while changing HTEI from 31 to $39 \mathrm{kV}$. However, a great influence of the second LEBT solenoid intensity (from 110 to $140 \mathrm{~A}$ ) is observed on the emittance value (from 0.4 to $0.23 \pi \mathrm{mm}$.mrad). The minimum value of $0.23 \pi \mathrm{mm}$.mrad has been measured downstream a cross over for a $70 \mathrm{~mA}$ proton beam.

\section{II-3 Optical diagnostics}

High intensity beam diagnostic development is an important issue of the SILHI program. The requested beam power density (close to $100 \mathrm{~mA}$ over $6 \mathrm{~mm}$ diameter) prohibits interceptive diagnostics at the IPHI RFQ entrance. Optical diagnostics are under development [7].

Direct Fluorescence Beam Profile Measurement with CCD camera ( $\mathrm{C} 1$ on Fig. 1) perpendicular to the beam direction allows valid beam centre position measurements. However, comparisons performed with electrical profiler in pulsed mode indicate some profile shape discrepancies. A second CCD camera (C2 on Fig. 1) was installed in the focal plane of a spectrometer (resolution better than $0.1 \mathrm{~nm}$ ). Doppler shift observation of the hydrogen Balmer series allows isolating the fluorescence only resulting from proton beam interaction with the residual gas. Doppler shift analysis shows a smaller beam size for the proton beam profile (compared with the $\mathrm{C} 1$ camera measurements). This difference is explained by the $\mathrm{H}_{2}^{+}$and $\mathrm{H}_{3}{ }^{+}$beams and also by second step processes involved in the fluorescence. The observed beam size difference remains constant whatever the beam size resulting in different focusing conditions. Extensive studies will be carried out to improve this method.

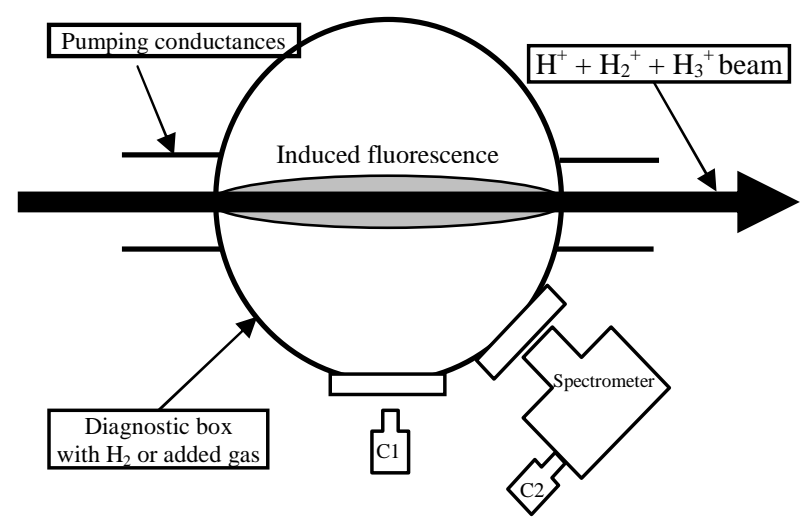

Fig.1: Experimental set up for fluorescence beam profile measurement.

\section{DEUTERON SOURCE DESIGN}

SPIRAL 2 is a new project under study at GANIL. The goal of this facility consists in extending the possible radioactive ion beam types [2]. While SPIRAL 1 uses the projectile fragmentation for radioactive nuclei production, SPIRAL 2 is based on the fission of a Uranium carbide target induced by neutrons. The neutron flow will be produced by interaction of deuteron beam with a Carbon target. SPIRAL 2 requires a maximum of $5 \mathrm{~mA}-40 \mathrm{keV} \mathrm{CW} \mathrm{D}^{+}$beam (at the RFQ entrance) with rms normalized emittances lower than $0.2 \pi$ mm.mrad.

Taking into account the deuteron experiments already successfully performed with SILHI $(130 \mathrm{~mA}$ at $100 \mathrm{keV}$ in pulsed mode) [8], the design of such a source fulfilling the SPIRAL 2 requirements has been undertaken. After the SILHI moving to the final site, a $70 \mathrm{~mA}$ proton beam has been rapidly obtained with classical magnetic configuration. This reproducible result authorizes us to propose a $2.45 \mathrm{GHz}$ ECR source of which the magnetic field is provided by permanent magnets. To obtain similar magnetic configuration, simulations have been carried out with OPERA-2D from VectorFields. The magnetic material characteristics were chosen with the GANIL group who routinely uses permanent magnets for heavy ion ECR sources. Moreover, code crosscheck has been achieved with the GANIL Poisson code.

As a result, a single $180 \mathrm{~mm}$ long $\mathrm{NdFeB}$ ring leads to an axial magnetic field (in the plasma chamber) similar to the SILHI configuration. Obviously, the inversed field does not exist on both sides with the coils. The use of permanent magnets does not lead to source exit emittance growth due to the inversed field [9]. In fact, three shorter (50 mm long) rings will allow a slight tuning by independently moving them. Each ring will be made of a 24 elementary $\mathrm{NdFeB}$ magnets assembled in an aluminum shell. The plasma chamber will keep the SILHI design with the RF window protected behind a bend, the ridged transition and the 2 Boron Nitride discs at both ends. 
In addition, to keep a high plasma density leading to higher deuteron fraction, the extraction system has been studied with a $2.5 \mathrm{~mm}$ diameter emission aperture. The maximum requested deuteron current is $5 \mathrm{~mA}$ but a second running mode asks for the ability to deliver only $150 \mu \mathrm{A}$ with comparable emittance. This imposes a flexible design [6]. This design will greatly help the accelerator conditioning which will demand a progressive increase of the current (from 0.1 to $5 \mathrm{~mA}$ ). To keep a small emittance, 2 tunable intermediate electrodes are envisaged (Fig. 2). A repeller will allow avoiding backstreaming electrons. No important space charge compensation is expected due to very low pressure in the LEBT. The $5 \mathrm{~mA} \mathrm{D} \mathrm{D}^{+}$beam simulations lead to an emittance value as small as $0.02 \pi \mathrm{mm}$.mrad.

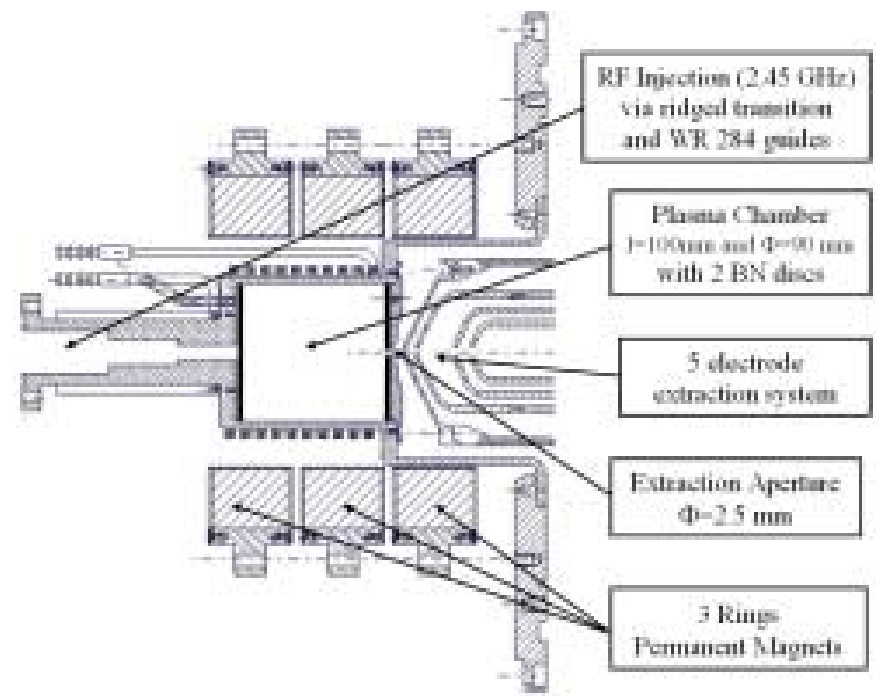

Fig.2: Drawing of the permanent magnet $2.45 \mathrm{GHz}$ ECR source designed to produce $5 \mathrm{~mA}$ of Deuteron beam

\section{H` TEST BENCH DEVELOPMENT}

The CEA/DSM decided to develop an $\mathrm{H}^{-}$ion source based on ECR plasma generator. Since the SILHI source demonstrated high density plasma performance, the same approach was chosen to couple the microwave to the plasma. At the beginning of 2002, the first hydrogen negative ion beam (only a few $\mu \mathrm{A}$ ) was produced [10].

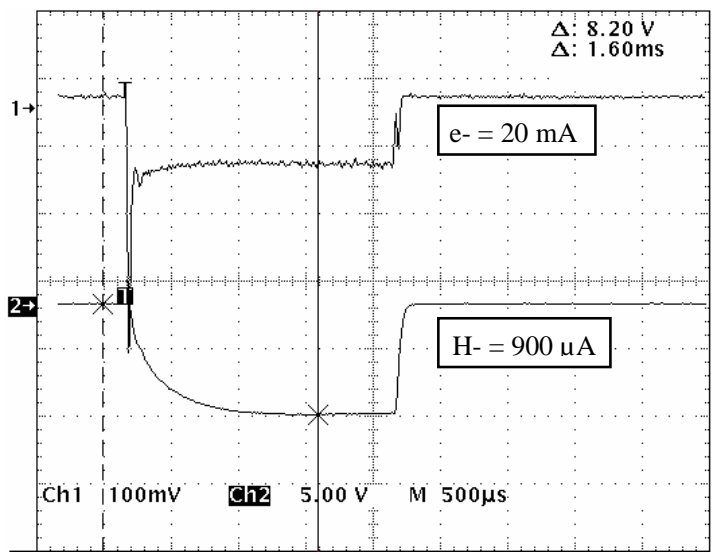

Fig 3: Separated $\mathrm{H}^{-}$and electron extracted beams (16 pulse average)
Nevertheless, specific lines easily observed with a spectrometer indicate the presence of excited hydrogen molecules able to produce $\mathrm{H}^{-}$ions. The small intensity of extracted negative ion has been attributed to ion destruction by the microwaves and high energy electrons. A stainless steel grid has been installed across the plasma chamber (at $85 \mathrm{~mm}$ from the extraction aperture) to avoid RF penetration up to the plasma electrode. Immediately the $\mathrm{H}^{-}$beam intensity increased by a factor of 2 . Then by adjusting the position of the grid in the plasma chamber, the current reached up to $80 \mu \mathrm{A}$. To optimize the electron energy in the production zone, the grid was biased by a power supply. A new jump has been observed and the source is now producing more than $800 \mu \mathrm{A} \mathrm{H}^{-}$ion current beam in pulsed mode (Fig. 3).

\section{ACKNOWLEDGMENTS}

The authors would like to thank all the IPHI group members who participate to the SILHI program, and G. Belyaev, B. Pottin and I. Roudskoy who help in diagnostic developments.

In addition, concerning the Deuteron source studies, people from the SPIRAL 2 group are also thanked especially M.H. Moscatello and J.M. De Conto. We do not forget L. Ando from INFN Catania who participated in fruitful discussions.

The $\mathrm{H}^{-}$ion source development is performed in the framework of a European network where 9 European laboratories are involved. The support of the European Community (Contract HPRI-CT-2001-50021) is gratefully acknowledged. Furthermore, we would like to thank G. Gousset from Orsay University for his help in $\mathrm{H}^{-}$studies.

\section{References}

[1] P-Y. Beauvais; Proceedings of EPAC conference, Paris, France, June 2002 (p. 539-541).

[2] R. Leroy et al.: "Status on radioactive ion production at GANIL and future projects", proceedings of this conference

[3] R. Gobin et al.: RSI, Vol.73, n², February 2002 (922)

[4] K. Benmeziane et al.: "Study and preliminary results for a new type of ECR H- ions source", proceedings of this conference

[5] R. Gobin et al.: "Development of an H- ion source based on ECR plasma generator at CEA/Saclay.", proceedings of this conference

[6] O. Delferrière et al.: "Extraction design and LEBT optimization of space charged multispecies ion beam sources", proceedings of this conference

[7] P. Ausset et al.; Proceedings of EPAC conference, Paris, France, June 2002, (p. 1840-1842).

[8] R. Ferdinand et al.; Proceedings of EPAC conference, Paris, France, June 2002, (p. 894-896)

[9] J. Mandin, "Etude experimentale et simulation des conditions d'extraction d'un faisceau d'ions multichargés d'une source ECR", Thesis, Caen University, December 1996.

[10] R. Gobin et al.; Proceedings of the $9^{\text {th }}$ Intern. Symposium on Negative Ion Sources and Beams, Saclay, France, May 2002, AIP Conference Proceedings, 639, pg: 177. 